\title{
Improved lithium-ion battery anode performance via multiple element approach
}

\author{
Turkan Gamze Ulusoy Ghobadi $^{\text {a, b }}$, Muharrem Kunduraci ${ }^{c,}$, Eda Yilmaz ${ }^{\text {a }}$ \\ ${ }^{a}$ UNAM - National Nanotechnology Research Center and Institute of Materials Science and Nanotechnology, Bilkent University, Ankara 06800, Turkey \\ ${ }^{\mathrm{b}}$ Department of Energy Engineering, Faculty of Engineering, Ankara University, Ankara 06830, Turkey \\ ${ }^{\mathrm{c}}$ Department of Mechanical Engineering, Faculty of Engineering, University of Turkish Aeronautical Association, Ankara 06790, Turkey
}

\section{A R T I C L E I N F O}

\section{Article history:}

Received 23 July 2017

Received in revised form

26 September 2017

Accepted 27 September 2017

Available online 28 September 2017

\section{Keywords:}

Lithium ion batteries

Conversion anodes

Multiple elements

\begin{abstract}
A B S T R A C T
In this work, single $\left(\mathrm{Co}_{3} \mathrm{O}_{4}\right)$, binary $\left(\mathrm{Co}_{3} \mathrm{O}_{4} / \mathrm{ZnO}\right)$ and ternary $\left(\mathrm{Co}_{3} \mathrm{O}_{4} / \mathrm{ZnO} / \mathrm{NiO}\right)$ nanomaterials were successfully synthesized by Pechini method followed by a calcination step. Electrochemical lithium storage capabilities of the anode materials were studied. The results showed that the best capacity retention and lowest voltage hysteresis was achieved with ternary material. The ternary material showed a first cycle charge capacity of $649 \mathrm{mAh} / \mathrm{g}$ at $70 \mathrm{~mA} / \mathrm{g}$ and maintained $83 \%$ of this capacity after 39 cycles. The results demonstrated the positive impact of multiple element strategy on the cycle life of anode materials.
\end{abstract}

๑) 2017 Elsevier B.V. All rights reserved.

\section{Introduction}

Since their first introduction to the market in 1991, there have been great interest on the progress in lithium-ion batteries (LIBs) to meet the rising demand for larger energy storage, particularly in full electric/hybrid vehicles, electric grid applications, power tools as well as portable electronics [1-3]. In order to build LIBs with high power and capacity, faster charging rate and long-lifetime, considerable efforts have been focused on the development of next-generation anode and cathode materials.

Graphite has been the well-known anode of choice in commercial LIBs due to its low cost, long cycle life and low working potential [4]. However, graphite has limited theoretical reversible capacity of $372 \mathrm{mAh} / \mathrm{g}$ [5]. Among various materials, transition metal oxides such as $\mathrm{Mn}_{2} \mathrm{O}_{3}$ [6], $\mathrm{ZnFe}_{2} \mathrm{O}_{4}$ [7], $\mathrm{NiO}$ [8], $\mathrm{Co}_{3} \mathrm{O}_{4}$ [9] have been recently in favor thanks to their low cost and high lithium capacities. The gravimetric capacities of these metal oxides range from 750 to $1200 \mathrm{mAh} / \mathrm{g}$ owing to conversion based reaction mechanism. Unfortunately, transition metal oxide anodes are prone to fast capacity decay due to large volume expansion during lithiation and poor reversibilities common in conversion reactions. To resolve these problems there have been many approaches which

\footnotetext{
* Corresponding author.

E-mail address: kunduraci.m@hotmail.com (M. Kunduraci).
}

can be categorized into: 1) the coating of anode materials with graphene [10-12], 2) the nanostructuring of anode particles [13-15] and 3) the use of electrolyte additives [16,17] to stabilize the particle surface against electrolyte decomposition. However; there are very few studies addressing the nature of conversion reaction and even less pertaining to its working mechanism, limited merely to mitigating the detrimental impacts of volumetric expansion. It is common notion that when transition metal oxides are fully discharged, the discharged products consist of nanosized metal $(\mathrm{M})$ particles dispersed within a lithium oxide $\left(\mathrm{Li}_{2} \mathrm{O}\right)$ matrix. In the following charging step, $\mathrm{M}$ is oxidized to $\mathrm{MO}_{\mathrm{x}}$, decomposing $\mathrm{Li}_{2} \mathrm{O}$ and releasing lithium ions. As the conversion reaction occurs between $\mathrm{M}$ and $\mathrm{Li}_{2} \mathrm{O}$, the extent of this reaction is strongly correlated with the chemical composition of the $\mathrm{M}$ and the overall contact area between the $\mathrm{M}$ particles and $\mathrm{Li}_{2} \mathrm{O}$ matrix. The amount of this contact area is influenced by the volume fraction and the size of $\mathrm{M}$ particles. Except the primary anode particle size; however, studies investigating the role of $\mathrm{M}$ composition and $\mathrm{M} / \mathrm{Li}_{2} \mathrm{O}$ mole (and volume) ratio on the reversibility of conversion reactions are very limited so far.

Dahn et al. [18] synthesized LiF/Fe nanocomposites at varying mole ratios using combinatorial sputtering method. They concluded that the nanocomposite exhibited the optimum performance at a ratio of 3 based on second discharge capacities. However, they did not provide further cycling data, which raises the question if the optimum ratio would stay the same. Graetz et al. [19] 
compared the electrochemical reversibility in $\mathrm{FeF}_{3}$ and $\mathrm{CuF}_{2}$. TEM (Transmission electron microscopy) and EELS (Electron energy loss spectroscopy) measurements revealed that in the lithiated state metallic iron nanoparticles are interconnected and less than $5 \mathrm{~nm}$ diameter, whereas metallic copper segregates into 5-12 nm nanoparticles. The authors argued that the much larger interface formed between nanoscale metal and LiF phases in the former material provided an easier pathway for ionic transport during the conversion process, thereby explaining the larger degree of conversion reaction.

Here, we will show that the use of multiple elements in transition metal oxide anodes can be a winning strategy to improve the capacity retention over single atom systems.

\section{Experimental section}

\subsection{Material synthesis}

Single $\left(\mathrm{Co}_{3} \mathrm{O}_{4}\right)$, binary $\left(\mathrm{Co}_{3} \mathrm{O}_{4} / \mathrm{ZnO}\right)$ and ternary $\left(\mathrm{Co}_{3} \mathrm{O}_{4} / \mathrm{ZnO} /\right.$ $\mathrm{NiO}$ ) oxide anodes were synthesized by Pechini process [20]. These materials will be denoted as $\mathrm{C}, \mathrm{CZ}$ and $\mathrm{CZN}$, in the text going forward. This process was chosen because of its suitability to enable atomic scale mixing of multiple elements. Briefly, the required amounts of $\mathrm{Co}(\mathrm{II})$ nitrate hexahydrate, $\mathrm{Zn}$ (II) nitrate hexahydrate and $\mathrm{Ni}(\mathrm{II})$ nitrate hexahydrate salts were dissolved in minimum amount of distilled water. The mole ratios of metals were $\mathrm{Co}: \mathrm{Zn}=2: 1$ for $\mathrm{CZ}$ and $\mathrm{Co}: \mathrm{Zn}: \mathrm{Ni}=1: 1: 1$ for $\mathrm{CZN}$. The aqueous solution was added dropwise to citric acid-ethylene glycol (1:4 mol ratio) solution kept at $90{ }^{\circ} \mathrm{C}$ until completion. Later, the viscous solution was further heated to $150{ }^{\circ} \mathrm{C}$ for esterification. The fully dried solid was ground and initially heated to $450{ }^{\circ} \mathrm{C}$ for $1 \mathrm{~h}$ in air to burn the organics and finally to $700{ }^{\circ} \mathrm{C}$ for $10 \mathrm{~h}$ to obtain crystalline structure.

\subsection{Materials characterization}

The morphological characteristics of the synthesized anode materials were performed using scanning electron microscope (SEM, FEI - Quanta 200 FEG) operated at $10 \mathrm{kV}$. Energy-dispersive $\mathrm{X}$-ray spectroscopy (EDX) analysis is also performed and SEM-EDX spectra are recorded for all samples. Powder X-ray diffraction (PXRD) has been carried out by Panalytical X'pert Multi-Purpose and the patterns have been collected in the range of $2 \theta=20-80^{\circ}$ using Bragg-Brentano geometry ( $\mathrm{Cu} \mathrm{K} \alpha$ radiation, $\lambda=0.15418 \mathrm{~nm}$ ). X-ray photoelectron spectroscopy (XPS, Thermoscientific K-Alpha, Al K-Alpha radiation, hu $=1486.6 \mathrm{eV}$ ) measurement has been performed at survey mode by operating flood gun to prevent surface charging with the pass energy and step size set to $30 \mathrm{eV}$ and $0.1 \mathrm{eV}$, respectively and performs for determining the elemental analysis. Peak positions correction were calibrated by referencing the $\mathrm{C} 1 \mathrm{~s}$ peak position $(284.8 \mathrm{eV})$ and shifting other peaks in the spectrum accordingly. For oxidation state characterization; moreover, depth profiling was carried out by using XPS with $\mathrm{Ar}+$ ions having energy of $1000 \mathrm{eV}$. The depth profiles of the samples were generated in 10 cycles, each XPS spectrum collected after exposing the sample to the gas cluster ion beam for 200 s. For SEM imaging of the samples after cycling, the cells were opened in glovebox and anode electrodes were recovered. Afterwards, they are washed with $2 \mathrm{~mL}$ acetonitrile and dried inside. Finally, they were immediately brought for SEM experiment.

\subsection{Electrochemical measurements}

In order to prepare the anode slurries, PVDF binder was dissolved in N-methyl-2-pyrrolidone (NMP) solvent. After clear solution was observed, first Super P as a conductive additive and later anode material were added to the PVDF/NMP solution. The slurry was kept under constant stirring for overnight. The slurry contained 70:15:15 weight ratios of anode: PVDF: conductive carbon materials, respectively. The electrode materials were vacuum dried at $70^{\circ} \mathrm{C}$ overnight, then rapidly put into argon filled glovebox $\left(\mathrm{O}_{2}<0.5 \mathrm{ppm}, \mathrm{H}_{2} \mathrm{O}<0.5 \mathrm{ppm}\right)$ to prevent air exposure. Swagelok type cells were used to build lithium half cells. Celgard C480 separators were utilized at anode while separators of the cathodes were glass microfiber filter $(\mathrm{GF} / \mathrm{C})$. The electrolyte solutions of the cells were composed of $280 \mu \mathrm{L}$ of $0.5 \mathrm{M}$ LiTFSI dissolved in EC:DMC $(1: 1)$ solution. The cells were sealed after the assembly to prevent interaction with the atmosphere, and rested at room temperature for $8 \mathrm{~h}$ prior to testing. Electrochemical tests were conducted with Landt CT2001 multichannel potentiostat/galvanostat at $70 \mathrm{~mA} / \mathrm{g}$ current rate between $0.2 \mathrm{~V}$ and $3 \mathrm{~V}$ versus $\mathrm{Li} / \mathrm{Li}$ + potential window. The active anode mass ranged from $2.1 \mathrm{mg}$ to $2.4 \mathrm{mg}$. The AC impedance spectroscopy analysis was carried out at the end of first charge (delithiation) step by applying $5 \mathrm{mV}$ alternating voltage. The frequency range was from $1 \mathrm{kHz}$ to $0.01 \mathrm{~Hz}$. The impedance data were normalized with respect to the active material amount in coin cells.

\section{Results and discussion}

In order to investigate the effect of multiple elements in transition metal oxide on the lithium-ion battery anode performance; single $\left(\mathrm{Co}_{3} \mathrm{O}_{4}\right)$, binary $\left(\mathrm{CO}_{3} \mathrm{O}_{4} / \mathrm{ZnO}\right)$ and ternary $\left(\mathrm{Co}_{3} \mathrm{O}_{4} / \mathrm{ZnO} / \mathrm{NiO}\right)$ oxide anodes were synthesized by Pechini method. In this synthetis process, single or multiple metal ions are dissolved in a solution, which transforms into a polymer gel upon heating on a hot plate. The atomic level mixing and the combustion of organic materials at high temperatures create porous metal oxides with a high degree of homogeneity.

The morphologies and structural characteristics of the synthesized composite anodes are performed by SEM. As shown in Fig. $1 \mathrm{a}-\mathrm{c}$, the sizes of the obtained $\mathrm{C}, \mathrm{CZ}$ and $\mathrm{CZN}$ particles decrease from $\sim 500$ to $700 \mathrm{~nm}$ for $C$ to $300-500 \mathrm{~nm}$ for $C Z$ and $200-500 \mathrm{~nm}$ for CZN. It is seen that the particle size tends to decrease with the introduction of more foreign atoms. This is based on the fact that the growth rate of crystals diminishes as more and more foreign atoms are introduced to the original material. In fact, we argue that this is one of the benefits of multiple element strategy. Since the reversibility of conversion materials is strongly dependent on the particle size, we expect improvement in electrochemical performance going from single atom system to ternary system. According to SEM images, the particles seem to be partially fused together with 100-200 nm sized pores separating each particle. This kind of porous and interconnected structure is expected to be conducive to both electronic transport as well as buffering volume expansion. In order to make sure that the binary and ternary materials are made of nanocomposites and not phase separated, EDX analysis was carried out at multiple spots. The elemental analysis revealed that the individual particles have homogeneous distribution of Co, $\mathrm{Zn}$ and Ni elements, confirming our earlier expectations (see Fig. S1).

X-ray diffraction analysis was performed to identify the crystalline structures of the obtained anode samples. The spectra (Fig. 2.a-c) clearly reveal that the diffraction peaks of the prepared $\mathrm{C}, \mathrm{CZ}$ and $\mathrm{CZN}$ are in agreement with the standard diffraction patterns of cubic $\mathrm{CO}_{3} \mathrm{O}_{4}$ (JCPDS, 98-006-9375), hexagonal $\mathrm{ZnO}$ (JCPDS, 98-005-7450), and hexagonal $\mathrm{NiO}$ (JCPDS, 98-016-6131) with the prominent peaks (113), (011) and (012), respectively. No other peaks were detected indicating the absence of other phases. However, best fittings were acquired when we assumed about $5 \%$ intermixing between $\mathrm{Co}, \mathrm{Zn}$ and $\mathrm{Ni}$ atoms. This is a reasonable 


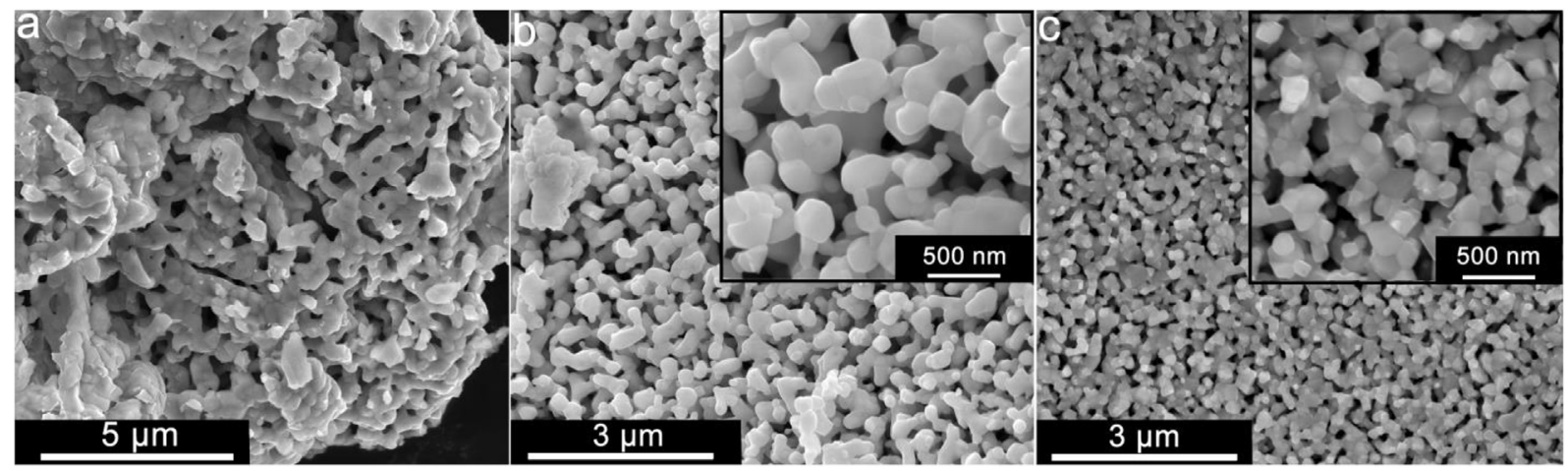

Fig. 1. SEM images of the (a) $\mathrm{Co}_{3} \mathrm{O}_{4}$ (b) $\mathrm{Co}_{3} \mathrm{O}_{4} / \mathrm{ZnO}$ (c) $\mathrm{Co}_{3} \mathrm{O}_{4} / \mathrm{ZnO} / \mathrm{NiO}$ anode powders obtained at $700{ }^{\circ} \mathrm{C}$ for $10 \mathrm{~h}$.

assumption given that all three atoms have +2 oxidation state.

The charge-discharge behavior of anode materials were examined at room temperature between $0.2 \mathrm{~V}$ and $3 \mathrm{~V}$. The current rates were $70 \mathrm{~mA} / \mathrm{g}$, corresponding to roughly $\mathrm{C} / 10$. The charge (delithiation) and discharge (lithiation) voltage profiles are shown in Fig. $3 a-c$. The single phase $C$ has a distinct discharge plateau around $0.9 \mathrm{~V}$ in the first cycle and $1.25 \mathrm{~V}$ in the following cycles. This plateau was assigned to the reduction of cobalt ions to $\mathrm{Co}^{0}$ metal in the literature [21]. The corresponding charge plateau can be noticed at $2.1-2.2 \mathrm{~V}$. These two plateaus are less noticeable in binary $\mathrm{CZ}$ and even less in ternary CZN materials. This might be due to partial overlapping with the reduction and oxidation peaks of $\mathrm{Zn}$ and $\mathrm{Ni}$ atoms.

The charge and discharge capacities of single $\mathrm{C}$, binary $\mathrm{CZ}$ and ternary CZN anode materials are plotted with respect to cycle number in Fig. 4a. The first cycle discharge capacities of C, CZ and CZN were 787, 1175 and $894 \mathrm{mAh} / \mathrm{g}$, respectively. These capacities are above the theoretical capacities of $C Z$ and $C Z N$. These extra capacities can be attributed to SEI formation and interfacial lithium storage $[22,23]$. The first cycle charge capacities for the same anode materials were 401,797 and $649 \mathrm{mAh} / \mathrm{g}$, corresponding to $51 \%$, $67.8 \%$ and $72.6 \%$ first cycle coulombic efficiencies, respectively. The average coulombic efficiency after the 5 th cycle was $98.7 \%$ for CZN and $98.3 \%$ for $\mathrm{C}$ and $\mathrm{CZ}$.

To have a better comparison, the percentage of charge capacity retention values for different anode materials are displayed in Fig. 4b. The fastest capacity fading was observed with binary $\mathrm{CZ}$ anode material. After revisiting the voltage profiles more carefully in Fig. 3, it seems that most of the charge capacity loss were stemming from shortening of plateau around $2.2 \mathrm{~V}$. At the $20^{\text {th }}$ cycle, this plateau almost disappeared. This does not mean that cobalt atoms no longer participate in the conversion reaction since there was still some of the discharge plateau at $1.25 \mathrm{~V}$ during cycling. The possible explanation of this change is that interfacial lithium storage overtakes the capacity load with each cycling. We see similar changes for single $C$ and ternary CZN materials albeit at a smaller magnitude and slower pace $[24,25]$.

It is worth noting that the reason for the disappearance of this plateau and the accompanying capacity loss might be due to the aggregation of metallic cobalt nanoparticles during cycling. This mechanism has been proposed as the culprit for capacity fading in conversion type battery materials [26]. This theory can be considered valid for both anode and cathode materials. Since the capacity loss takes place at a much slower pace with ternary CZN system than binary $C Z$ system, we argue that the second benefit of multiple element strategy is that the presence of foreign atoms in the adjacent grains might block the migration of cobalt atoms, resulting in slower aggregation and capacity fading rates.
Since the conversion reaction takes place across the metal and $\mathrm{Li}_{2} \mathrm{O}$ interface, the size of the metal nanoparticles dispersed within the $\mathrm{Li}_{2} \mathrm{O}$ matrix plays a critical role on the reversibility of conversion reactions. For full reversibility, the size of metal nanoparticles needs to start and stay below a certain threshold throughout extensive cycling.

More specifically, the low charge capacity of single phase $\mathrm{CO}_{3} \mathrm{O}_{4}$, might be due to the appearance of larger than ideal metallic cobalt nanoparticles upon first discharge step. In this scenario, Co metal is oxidized to $\mathrm{CoO}$ and/or $\mathrm{Co}_{2} \mathrm{O}_{3}$ at the surface and but remain $\mathrm{Co}^{0}$ in the core. With the partial replacement of $\mathrm{Co}_{3} \mathrm{O}_{4}$ with $\mathrm{ZnO}$ in the starting material, the size of cobalt nanoparticles might have been reduced, justifying the much higher charge capacity. For example, the diameter of metal nanoparticles at full lithiation seems to be in the range of 5-10 $\mathrm{nm}[19,27,28]$. Hence, we may conclude that even a small decrease in particle diameter would significantly increase the fraction of metal atoms near the surface zone.

Recently, the positive impact of high-rate lithiation on the cycle life of $\mathrm{Co}_{3} \mathrm{O}_{4}$ anode material was demonstrated [29]. The improvement was attributed to the refinement of mesoporous architecture and the appearance of a more stable and thinner solidelectrolyte interface. It is a well-known fact that as the cooling rate of a molten metal increases, the grain size in the final structure decreases. In the same logic, the size of metallic cobalt nanoparticles distributed within the $\mathrm{Li}_{2} \mathrm{O}$ matrix might be getting smaller with increasing lithiation rates, hence explaining the electrochemical improvement.

In order to track the oxidation states of metals as well as to identify the source of charge capacity, XPS depth profiling was performed at the end of first full delithiation (charging) step for all three samples. Fig. 5a-f illustrates the XPS spectra of Co 2p, Ni 2p, and $\mathrm{Zn} 2 \mathrm{p}$ electronic levels in $\mathrm{C}, \mathrm{CZ}$ and $\mathrm{CZN}$ anode materials. The fitted profiles for the last etching cycle are also provided in Fig. S2. The peaks positioned around $780 \mathrm{eV}$ and $795 \mathrm{eV}$ correspond to Co $2 \mathrm{p} 3 / 2$ and Co $2 \mathrm{p} 1 / 2$ spin-orbit-split doublet peaks, respectively (Fig. 5 a, c, f). For samples $C Z$ and $C Z N$, we identified two major peaks with binding energies of $780.5 \mathrm{eV}$ and $779.5 \mathrm{eV}$ assigned to $\mathrm{Co}^{2+}$ and $\mathrm{Co}^{3+}$, consistent with previous reports [30-33]. Moreover, the $01 \mathrm{~s}$ spectra for these samples have been measured and plotted in Fig. S3 a-c.

According to the XPS depth profiles in Fig. 5a, b and d, the cobalt atoms can be oxidized up to $3+$ state in the charging step as it would imply high charging capacities. It is also noticeable that the relative ratios of $3+$ to 2 + peaks for both samples increased slightly towards the core of particles as the etching time increases. Keeping in mind these results, it may be concluded that for higher conversion efficiencies are achieved away from the particle surface, or there can be small self-discharge of cells prior to opening for XPS 


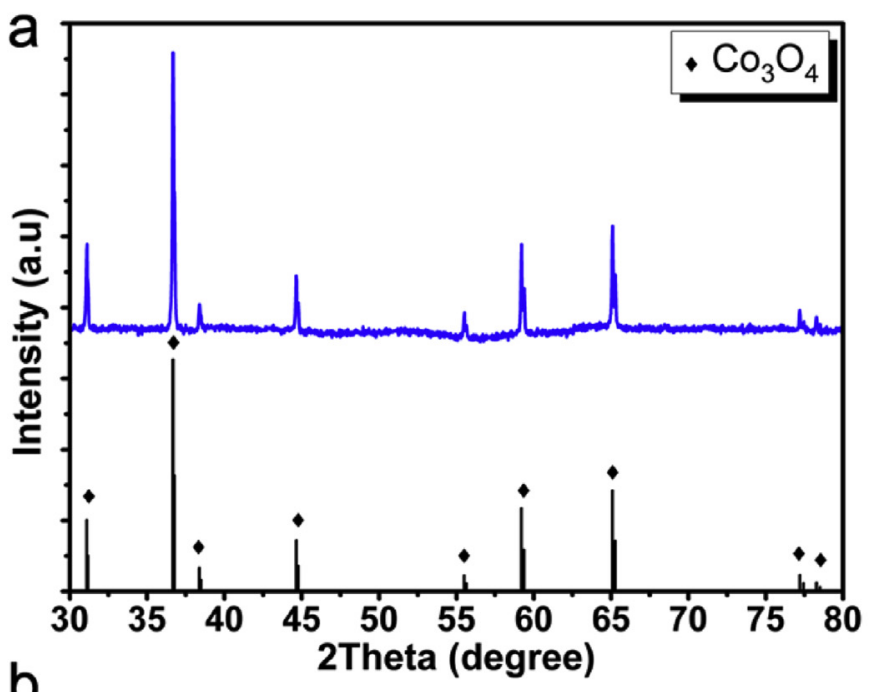

b

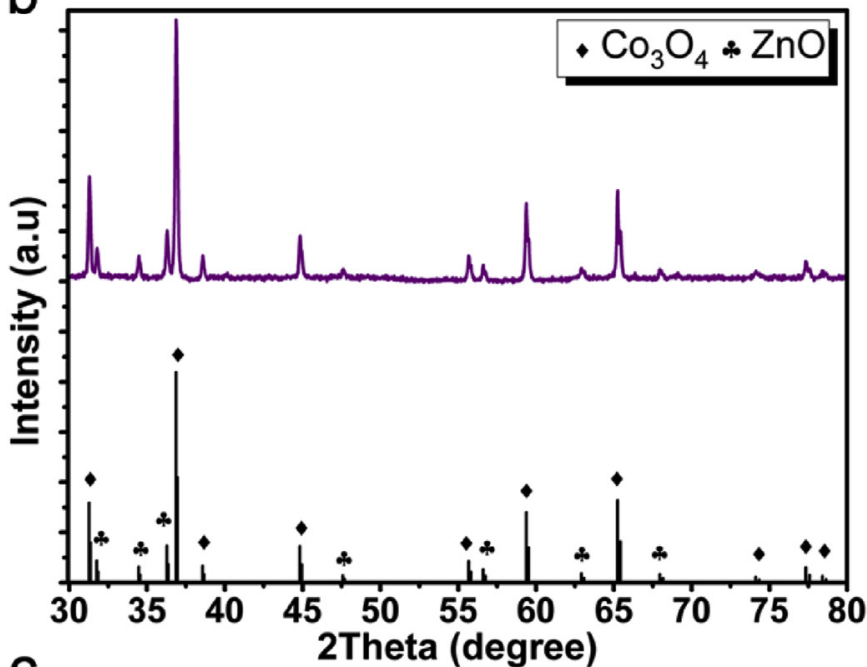

$\mathrm{c}$

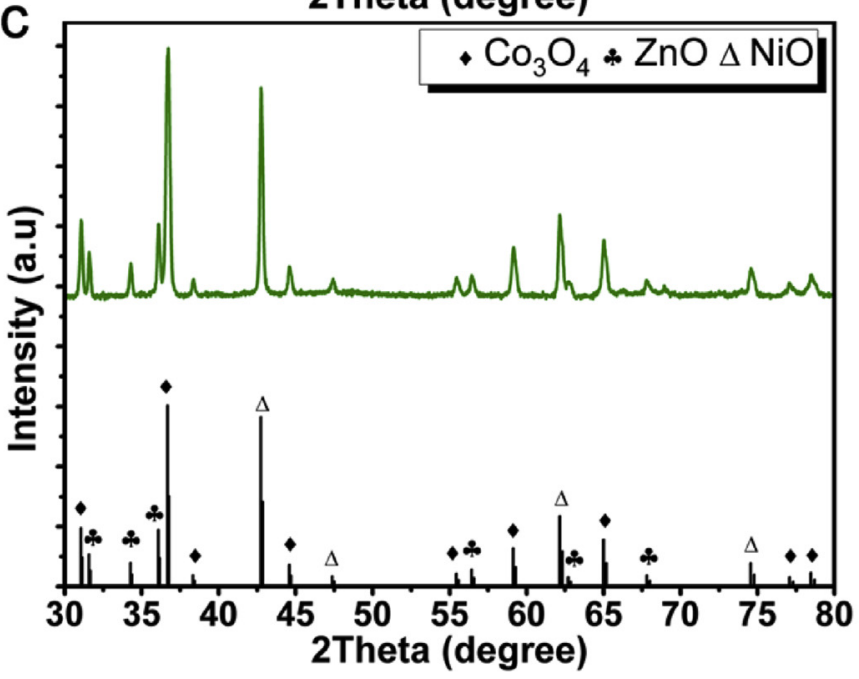

Fig. 2. XRD patterns of the anode films (a) $\mathrm{Co}_{3} \mathrm{O}_{4}$ (b) $\mathrm{Co}_{3} \mathrm{O}_{4} / \mathrm{ZnO}$ (c) $\mathrm{Co}_{3} \mathrm{O}_{4} / \mathrm{ZnO} / \mathrm{NiO}$.

studies. This effect is more prominent in sample CZ. A small selfdischarge could cause lithiation of anode particles and so, there is reduction of cobalt $3+$ ions to $2+$ near the surface. However, a further understanding should be pursued.

The cobalt peaks of sample $C$ showed significant change from the other two samples. A separate peak located at $\sim 778 \mathrm{eV}$ was
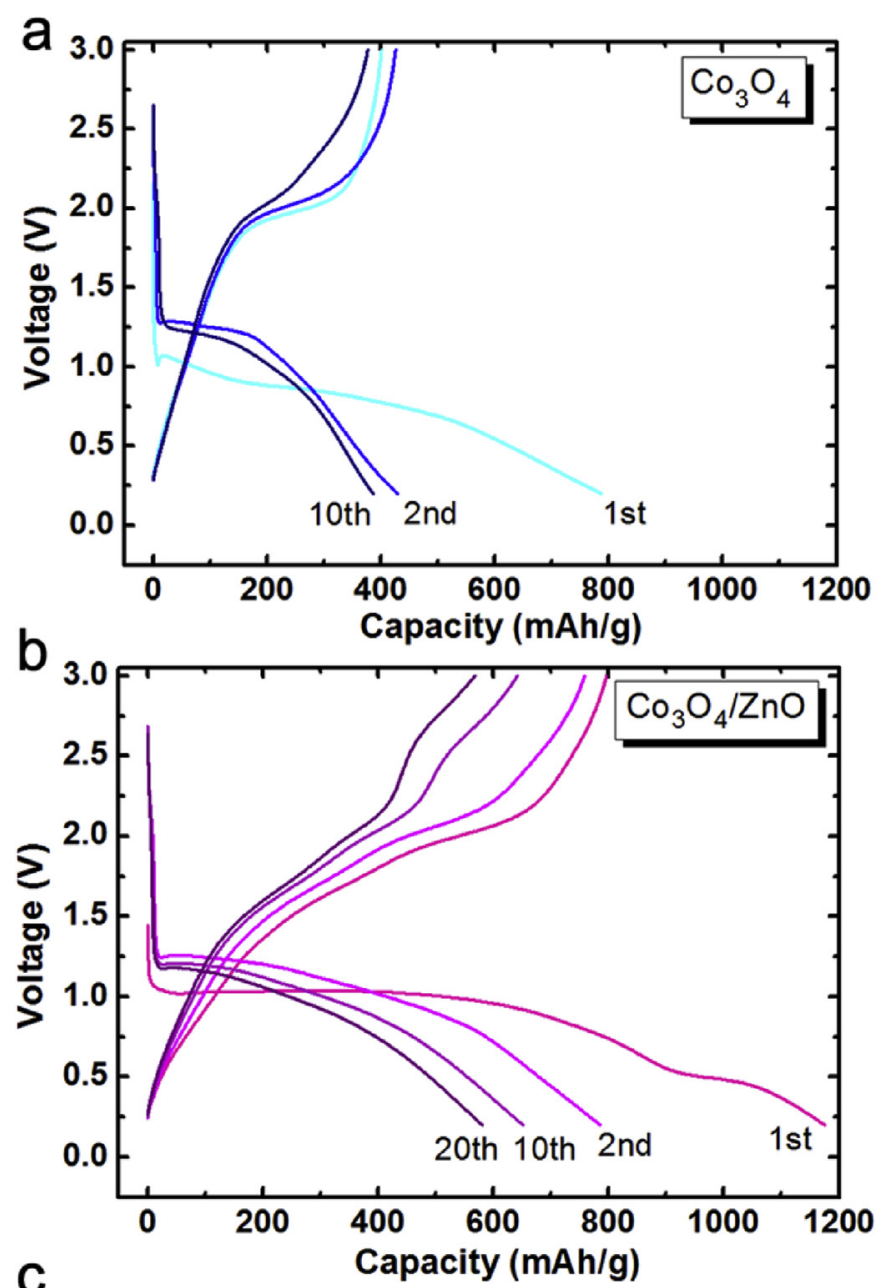

C

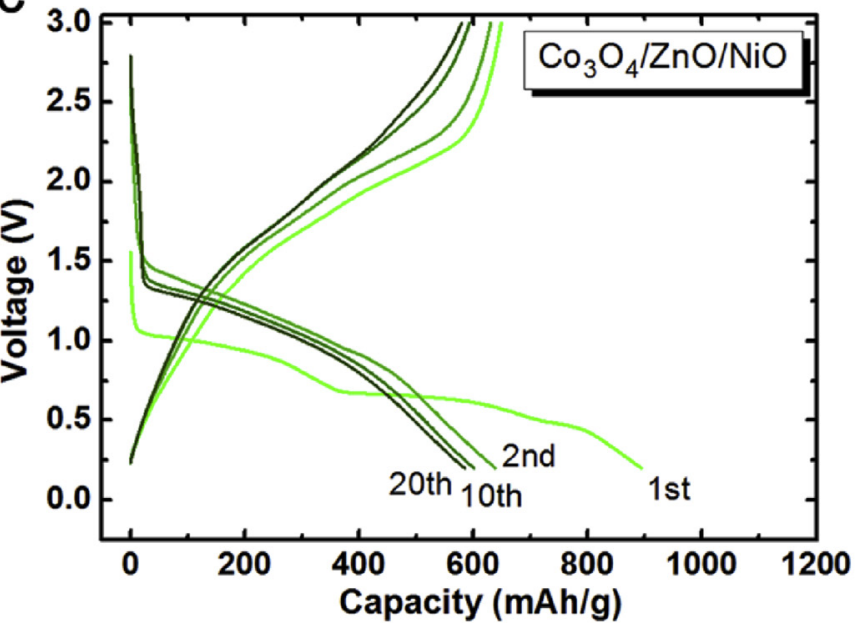

Fig. 3. Charge-Discharge voltages curves of (a) $\mathrm{Co}_{3} \mathrm{O}_{4}$ (b) $\mathrm{Co}_{3} \mathrm{O}_{4} / \mathrm{ZnO}$ (c) $\mathrm{Co}_{3} \mathrm{O}_{4} / \mathrm{ZnO} /$ $\mathrm{NiO}$ anode electrodes.

noticed, which belongs to unoxidized cobalt atoms, $\mathrm{Co}^{0}$ [34]. The irreversible formation of Co nanoparticles during discharging explains the much smaller charge capacity of sample $C$ than those of other two anodes.

Similar peak identification processes were performed for $\mathrm{Zn}$ and $\mathrm{Ni}$ atoms as well. We identified two peaks for zinc positioned around $1022 \mathrm{eV}$ and $1045 \mathrm{eV}$. These peaks were assigned to $\mathrm{Zn} 2 \mathrm{p} 3 /$ 2 and $\mathrm{Zn} 2 \mathrm{p} 1 / 2$ orbitals, respectively [35-37]. Comparing the XPS 

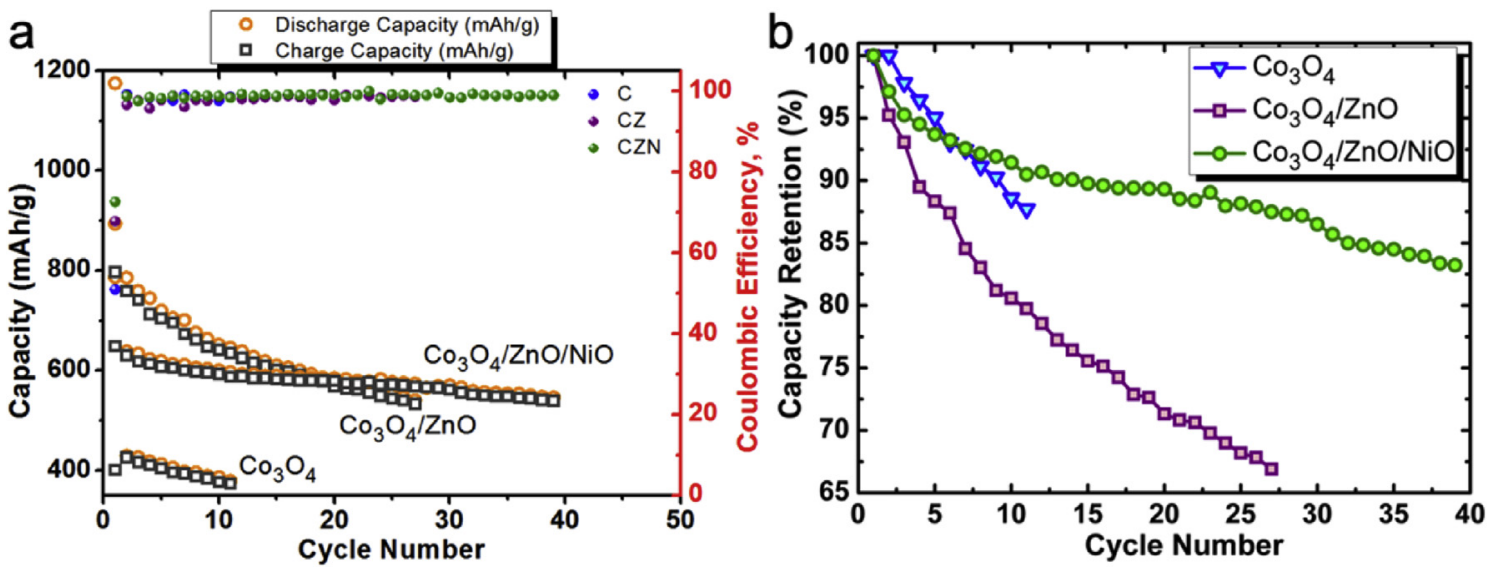

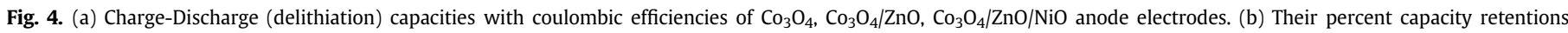
relative to first cycle.
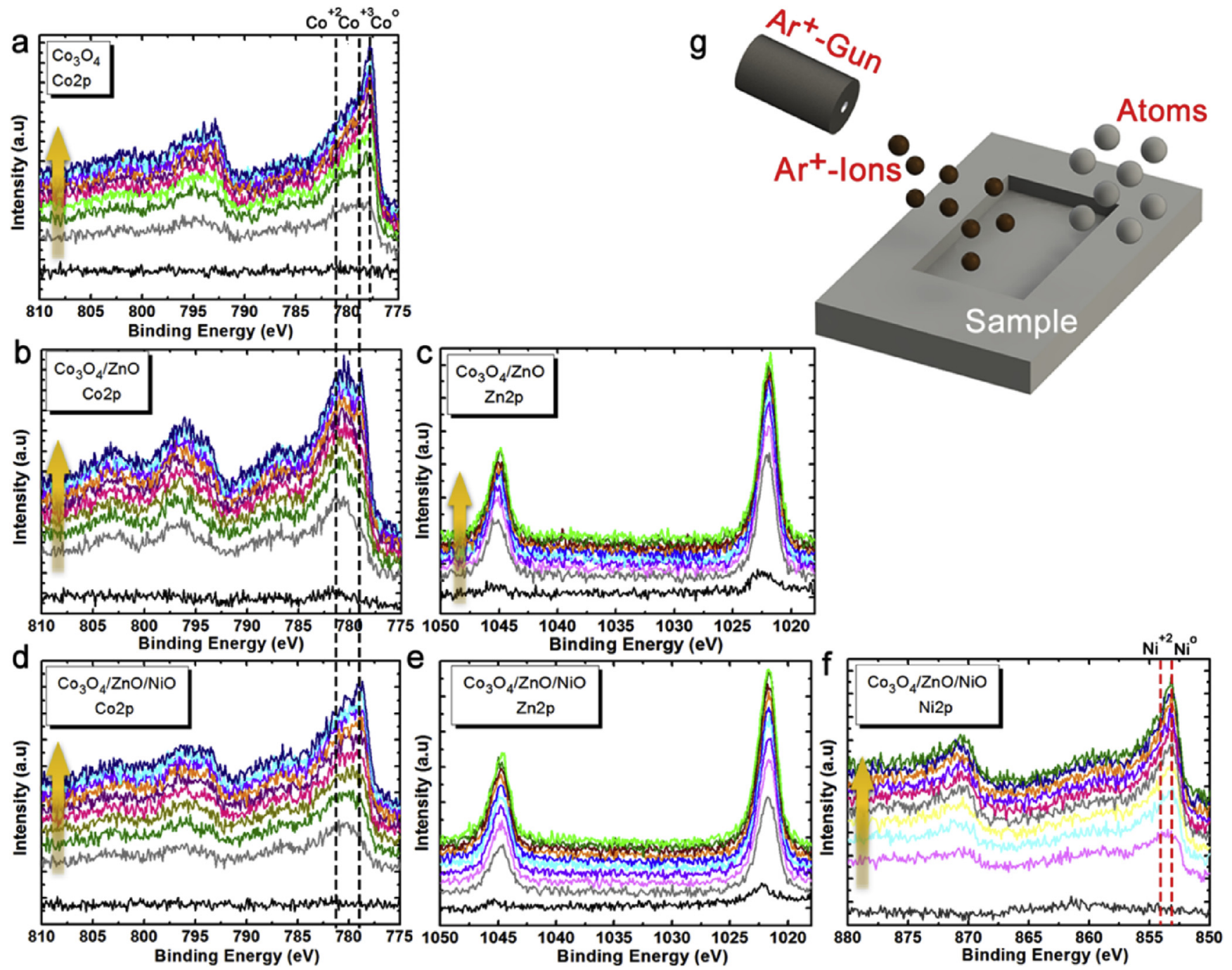

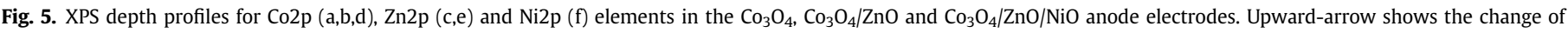
profiles during the total etching time of $30 \mathrm{~min}$. (g) Schematic illustration of etching process utilizing $\mathrm{Ar}$ gun.

data at different depths with those from fresh samples, we concluded that zinc atoms are fully oxidized to $2+$ state in both binary $\mathrm{CZ}$ and ternary $\mathrm{CZN}$ materials, thereby contributing to the charge capacity. As for nickel; however, oxidation to full $2+$ state does not seem to have realized. The best deconvolution of nickel profiles in ternary anode CZN was obtained when we assumed two 
peaks located at $\sim 853 \mathrm{eV}$ and $\sim 854$, and these peaks were assigned to $\mathrm{Ni}^{0}$ and $\mathrm{Ni}^{2+}$, respectively [38]. The presence of $\mathrm{Ni}^{0}$ states that nickel metal nanoparticles in fully discharged state can not be completely oxidized back to their original $2+$ state. This helps to explain why charge capacity in ternary anode material is lower than expected. In addition, the relative percentage of $\mathrm{Ni}^{0}$ seems to slightly increase, as we get closer to the core of the particle. Realizing that this trend is opposite to that of cobalt atoms in CZN, a fight between cobalt and nickel atoms for oxygen anions might be speculated.

XPS results verified that the binary and ternary materials consist of nanocomposites of $\mathrm{Co}_{3} \mathrm{O}_{4}, \mathrm{ZnO}$ and $\mathrm{NiO}$. This is based on the fact that at any point where XPS data were collected, we were able to gather information from all three metals. In addition, the $\mathrm{Co} 2 \mathrm{p}$ and O1s XPS spectra of the fresh samples in the $\mathrm{Co}_{3} \mathrm{O}_{4}, \mathrm{Co}_{3} \mathrm{O}_{4} / \mathrm{ZnO}$ and $\mathrm{Co}_{3} \mathrm{O}_{4} / \mathrm{ZnO} / \mathrm{NiO}$ anode electrodes are compared in Fig. S4. Moreover, the SEM images, EDX analysis and elemental mapping of the samples after charging has been provided in Fig. S5, Fig. S6, and Fig. S7, respectively.

To gain better insight into why ternary system outperforms the binary and single atom systems, the voltage hysteresis (or polarization) of the anode electrodes and their AC impedance analyses were explored. These can be used as efficient tools to compare different anode chemistries since there is a direct link between the amount of polarization and kinetically limited mechanisms. These mechanisms include charge transfer resistance, diffusion resistance for lithium ions within anode particles and electrical resistance of electrode.

Fig. 6 shows that the differences between average charge and discharge voltages as a function of cycle number for three different anode materials. The average charge and discharge voltage values of a given anode material were calculated by dividing its energy density $(\mathrm{mWh} / \mathrm{g})$ to its specific capacity $(\mathrm{mAh} / \mathrm{g})$ at that particular cycle number. The voltage scans were between $3 \mathrm{~V}$ and $0.2 \mathrm{~V}$. The lowest polarization was achieved with ternary CZN chemistry and kept itself same during the whole time of electrochemical testing.

At Fig. 7, the Z-plot data of three anodes are provided after one full charge. The arcs in the medium frequency range $(1 \mathrm{kHz}-10 \mathrm{~Hz})$ were assigned to the charge transfer resistance. The binary anode material has the highest charge transfer resistance while single atom and ternary anodes have much smaller resistance. We think that the presence of unoxidized cobalt and nickel metal particles in $\mathrm{C}$ and CZN anodes, respectively as observed in XPS analyses, helps the electronic conductivity of the electrodes, resulting in lower charge transfer resistances. We argue that the third benefit of

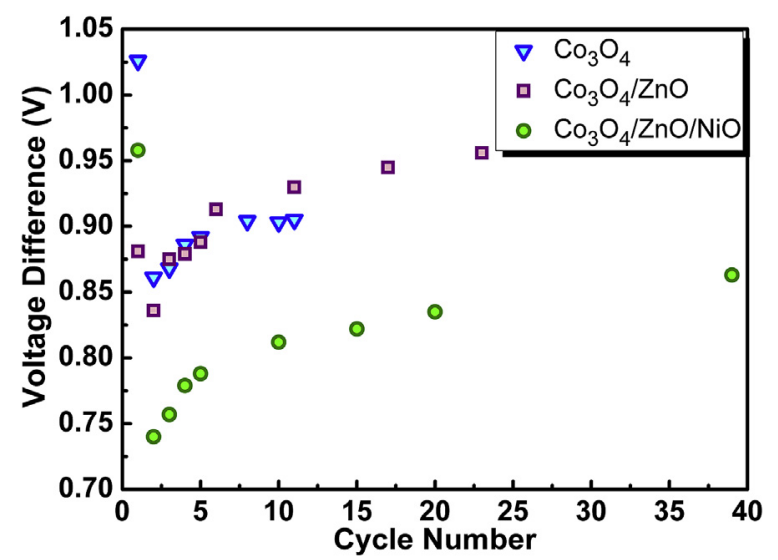

Fig. 6. Difference between average charge and discharge voltages as a function of cycle number.

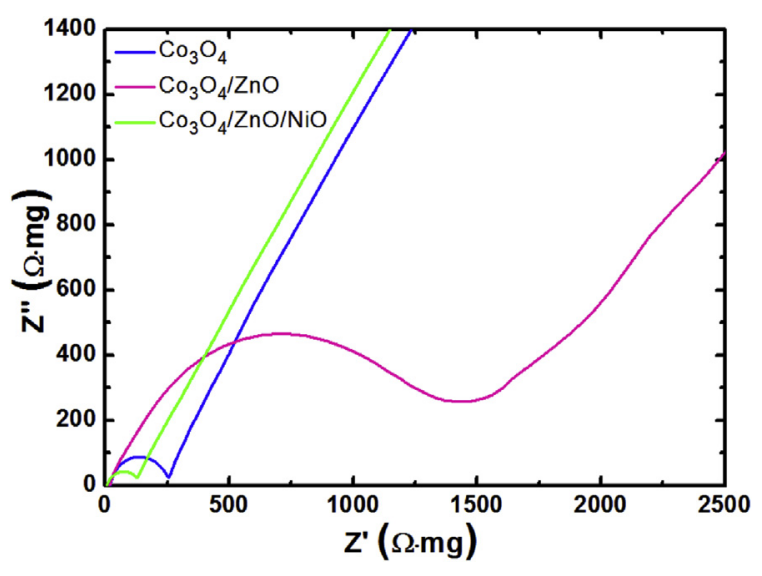

Fig. 7. Impedance spectra of $C, C Z$, and CZN materials at fully charged state.

multiple element strategy can be the introduction of a specific metal that does not fully convert back to oxide state during charging step. We witness such behavior with nickel ions in ternary CZN anode. While cobalt and zinc ions contribute to the capacity, nickel atoms partially stay in metallic state, thereby helping the electronic conductivity of the anode nanocomposite.

\section{Conclusions}

In this work, we argued that utilizing multiple elements would result in smaller primary particle size as well as slow down the aggregation rate of nanosized metal particles in the lithiated state, thereby helping to maintain surface activity and electrochemical performance in LIBs. Also, by introducing a specific metal such as nickel in ternary $\mathrm{CZN}$, the electronic conductivity of the nanocomposite can be improved. For this aim, single $\mathrm{Co}_{3} \mathrm{O}_{4}$, binary $\mathrm{Co}_{3} \mathrm{O}_{4} / \mathrm{ZnO}$ and ternary $\mathrm{Co}_{3} \mathrm{O}_{4} / \mathrm{ZnO} / \mathrm{NiO}$ oxide anode materials were successfully synthesized by Pechini method. The battery testing results demonstrated the winning nature of multiple element strategy with transition metal oxide anode materials in terms of highest percentage capacity retention and lowest polarization in ternary composite material. The use of multiple element strategy has already shown positive results in other fields such as high entropy alloys. We think that the adoption of this strategy will be more commonplace in future energy storage and conversion applications.

\section{Acknowledgments}

This research did not receive any specific grant from funding agencies in the public, commercial, or not-for-profit sectors.

\section{Appendix A. Supplementary data}

Supplementary data related to this article can be found at https://doi.org/10.1016/j.jallcom.2017.09.297.

\section{References}

[1] N. Nitta, F. Wu, J.T. Lee, G. Yushin, Li-ion battery materials: present and future, Mater. Today 18(2015) 252-264, https://doi.org/10.1016/j.mattod.2014.10.040.

[2] D. Deng, Li-ion batteries: basics, progress, and challenges, Energy Sci. Eng. 3 (2015) 385-418, https://doi.org/10.1002/ese3.95.

[3] C. Liu, Z.G. Neale, G. Cao, Understanding electrochemical potentials of cathode materials in rechargeable batteries, Mater. Today 19 (2016) 109-123, https:// doi.org/10.1016/j.mattod.2015.10.009.

[4] N. Wang, H. Xu, L. Chen, X. Gu, J. Yang, Y. Qian, A general approach for MFe2O4 $(\mathrm{M}=\mathrm{Zn}, \mathrm{Co}, \mathrm{Ni})$ nanorods and their high performance as anode materials for 
lithium ion batteries, J. Power Sources 247 (2014) 163-169, https://doi.org/ 10.1016/j.jpowsour.2013.08.109.

[5] S. Goriparti, E. Miele, F.D. Angelis, E.D. Fabrizio, R.P. Zaccaria, C. Capiglia, Review on recent progress of nanostructured anode materials for Li-ion batteries, J. Power Sources 257 (2014) 421-443, https://doi.org/10.1016/ j.jpowsour.2013.11.103.

[6] L. Hu, Y. Sun, F. Zhang, Q. Chen, Facile synthesis of porous Mn2O3 hierarchical microspheres for lithium battery anode with improved lithium storage properties, J. Alloys Compd. 576 (2013) 86-92, https://doi.org/10.1016/ j.jallcom.2013.04.146.

[7] X.B. Zhong, Z.Z. Yang, H.Y. Wang, L. Lu, B. Jin, M. Zha, Q.C. Jiang, A novel approach to facilely synthesize mesoporous $\mathrm{ZnFe} 2 \mathrm{O} 4$ nanorods for lithium ion batteries, J. Power Sources 306 (2016) 718-723, https://doi.org/10.1016/ j.jpowsour.2015.12.102.

[8] Q. Wang, C.Y. Zhang, W.F. Shan, L.L. Xing, X.Y. Xue, Uniformly loading NiO nanowalls on graphene and their extremely high capacity and cyclability as anodes of lithium-ion batteries, Mater. Lett. 118 (2014) 66-68, https:// doi.org/10.1016/j.matlet.2013.12.011.

[9] G.L. Xu, J.T. Li, L. Huang, W. Lin, S.G. Sun, Synthesis of Co3O4 nano-octahedra enclosed by $\{111\}$ facets and their excellent lithium storage properties as anode material of lithium ion batteries, Nano Energy 2 (2013) 394-402, https://doi.org/10.1016/j.nanoen.2012.11.005.

[10] Y.T. Xu, Y. Guo, C. Li, X.Y. Zhou, M.C. Tucker, X.Z. Fu, R. Sun, C.P. Wong, Graphene oxide nano-sheets wrapped Cu2O microspheres as improved performance anode materials for lithium ion batteries, Nano Energy 11 (2015) 38-47, https://doi.org/10.1016/j.nanoen.2014.10.011.

[11] P. Wu, X. Xu, Q. Zhu, X. Zhu, Y. Tang, Y. Zhou, T. Lu, Self-assembled graphenewrapped $\mathrm{SnO} 2$ nanotubes nanohybrid as a high-performance anode material for lithium-ion batteries, J. Alloys Compd. 626 (2015) 234-238, https:/] doi.org/10.1016/j.jallcom.2014.12.037.

[12] Y. Zhao, Y. Huang, X. Sun, H. Huang, K. Wang, M. Zong, Q. Wang, Hollow $\mathrm{Zn} 2 \mathrm{SnO} 4$ boxes wrapped with flexible graphene as anode materials for lithium batteries, Electrochim. Acta 120 (2014) 128-132, https://doi.org/ 10.1016/i.electacta.2013.12.098.

[13] Y. Chen, B. Liu, W. Jiang, Q. Liu, J. Liu, J. Wang, H. Zhang, X. Jing, Coaxial threedimensional CoMoO4 nanowire arrays with conductive coating on carbon cloth for high-performance lithium ion battery anode, J. Power Sources 300 (2015) 132-138, https://doi.org/10.1016/j.jpowsour.2015.09.011.

[14] J.S. Kim, A.Y. Kim, Y.W. Byeon, J.P. Ahn, D. Byun, J.K. Lee, Porous Zn2GeO4 nanowires with uniform carbon-buffer layer for lithium-ion battery anodes with long cycle life, Electrochim. Acta 195 (2016) 43-50, https://doi.org/ 10.1016/j.electacta.2016.02.118.

[15] L. Zhan, S. Wang, L.X. Ding, Z. Li, H. Wang, Grass-like Co3O4 nanowire arrays anode with high rate capability and excellent cycling stability for lithium-ion batteries, Electrochim. Acta 135 (2014) 35-41, https://doi.org/10.1016/ j.electacta.2014.04.139.

[16] A. Birrozzi, F. Maroni, R. Raccichini, R. Tossici, R. Marassi, F. Nobili, Enhanced stability of $\mathrm{SnSb} /$ graphene anode through alternative binder and electrolyte additive for lithium ion batteries application, J. Power Sources 294 (2015) 248-253, https://doi.org/10.1016/j.jpowsour.2015.06.065.

[17] V. Etacheri, O. Haik, Y. Goffer, G.A. Roberts, I.C. Stefan, R. Fasching, Effect of fluoroethylene carbonate (FEC) on the performance and surface chemistry of Si-nanowire li-ion battery anodes, Langmuir 28 (2012) 965-976, https:// doi.org/10.1021/la203712s.

[18] P. Liao, B.L. MacDonald, R.A. Dunlap, J.R. Dahn, Combinatorially prepared [LiF] $1-\mathrm{x}$ Fe $\mathrm{x}$ nanocomposites for positive electrode materials in Li-Ion batteries, Chem. Mater. 20 (2008) 454-461, https://doi.org/10.1021/cm702656k.

[19] F. Wang, R. Robert, N.A. Chernova, N. Pereira, F. Omenya, F. Badway, X. Hua, M. Ruotolo, R. Zhang, L. Wu, V. Volkov, D. Su, B. Key, M.S. Whittingham, C.P. Grey, G.G. Amatucci, Y. Zhu, J. Graetz, Conversion reaction mechanisms in lithium ion batteries: study of the binary metal fluoride electrodes, J. Am. Chem. Soc. 133 (2011) 18828-18836, https://doi.org/10.1021/ja206268a.

[20] M. Kunduraci, G.G. Amatucci, Synthesis and characterization of nanostructured 4.7 V LixMn1.5Ni0.504 spinels for high-power lithium-ion batteries, J. Electrochem. Soc. 153 (2006) A1345, https://doi.org/10.1149/ 1.2198110
[21] B.M. Chae, E.S. Oh, Y.K. Lee, Conversion mechanisms of cobalt oxide anode for Li-ion battery: in situ X-ray absorption fine structure studies, J. Power Sources 274 (2015) 748-754, https://doi.org/10.1016/j.jpowsour.2014.10.108.

[22] M. Dolle, P. Poizot, L. Dupont, J.M. Tarascon, Experimental evidence for electrolyte involvement in the reversible reactivity of $\mathrm{CoO}$ toward compounds at low potential, Electrochem. Solid State Lett. 5 (2002) A18-A21, https:// doi.org/10.1149/1.1425262.

[23] P. Balaya, A.J. Bhattacharyya, J. Jamnik, Y.F. Zhukovskii, E.A. Kotomin, J. Maier Nano-ionics in the context of lithium batteries, J. Power Sources 159 (2006) 171-178, https://doi.org/10.1016/j.jpowsour.2006.04.115.

[24] P. Lavela, J. Tirado, 57Fe mössbauer spectroscopy study of the electrochemica reaction with lithium of $\mathrm{MFe} 2 \mathrm{O} 4(\mathrm{M}=\mathrm{Co}$ and $\mathrm{Cu}$ ) electrodes, J. Phys. Chem. C 113 (2009) 20081-20087. http://pubs.acs.org/doi/abs/10.1021/jp9056362.

[25] C.V. Abarca, P. Lavela, J.L. Tirado, On the role of faradaic and capacitive contributions in the electrochemical performance of $\mathrm{CoFe} 2 \mathrm{O} 4$ as conversion anode for Li-ion cells, Solid State Ionics 181 (2010) 616-622, https://doi.org/ 10.1016/j.ssi.2010.02.028.

[26] M. Bomio, P. Lavela, J.L. Tirado, 57Fe Mössbauer spectroscopy and electron microscopy study of metal extraction from CuFe2O4 electrodes in lithium cells ChemPhysChem 8(2007)1999-2007, https://doi.org/10.1002/cphc.200700331.

[27] A. Debart, L. Dupont, P. Poizot, J.B. Leriche, J.M. Tarascon, A transmission electron microscopy study of the reactivity mechanism of tailor-made CuO particles toward lithium, J. Electrochem. Soc. 148 (2001) A1266, https:// doi.org/10.1149/1.1409971.

[28] K. Zhong, X. Xia, B. Zhang, H. Li, Z. Wang, L. Chen, MnO powder as anode active materials for lithium ion batteries, J. Power Sources 195 (2010) 3300-3308, https://doi.org/10.1016/j.jpowsour.2009.11.133.

[29] H. Sun, G. Xin, T. Hu, M. Yu, D. Shao, X. Sun, J. Lian, High-rate lithiationinduced reactivation of mesoporous hollow spheres for long-lived lithiumion batteries, Nat. Commun. 5 (2014) 1-8, https://doi.org/10.1038/ ncomms5526.

[30] Z. Chen, S. Wang, W. Liu, X. Gao, D. Gao, M. Wang, S. Wang, Morphologydependent performance of $\mathrm{Co} 3 \mathrm{O} 4$ via facile and controllable synthesis for methane combustion, Appl. Catal. A Gen. 525 (2016) 94-102, https://doi.org 10.1016/j.apcata.2016.07.009.

[31] Z. Pu, H. Zhou, Y. Zheng, W. Huang, X. Li, Enhanced methane combustion over Co3O4 catalysts prepared by a facile precipitation method: effect of aging time, Appl. Surf. Sci. 410 (2017) 14-21, https://doi.org/10.1016 j.apsusc.2017.02.186.

[32] A. Amri, X. Duan, C.Y. Yin, Z.T. Jiang, M.M. Rahman, T. Pryor, Solar absorptance of copper-cobalt oxide thin film coatings with nano-size, grain-like morphology: optimization and synchrotron radiation XPS studies, Appl. Surf. Sci. 275 (2013) 127-135, https://doi.org/10.1016/j.apsusc.2013.01.081.

33] J. Ahn, J. Park, H. Sim, W. Lee, S. Han, C. Shin, Catalytic combustion of lean methane at low temperature over ZrO2-modified Co3O4 catalysts, Appl. Surf. Sci. 3 (2017) 85-93, https://doi.org/10.1016/j.apsusc.2017.05.231.

[34] Y.I. Choi, H.J. Yoon, S.K. Kim, Y. Sohn, Crystal-facet dependent CO oxidation, preferential oxidation of $\mathrm{CO}$ in $\mathrm{H} 2$-rich, water-gas shift reactions, and supercapacitor application over Co304 nanostructures, Appl. Catal. A Gen. 519 (2016) 56-67, https://doi.org/10.1016/j.apcata.2016.03.027.

35] T.G. Ulusoy, A. Ghobadi, A.K. Okyay, Surface engineered angstrom thick $\mathrm{ZnO}$ sheathed TiO2 nanowires as photoanodes for performance enhanced dyesensitized solar cells, J. Mater. Chem. A 2 (2014) 16867-16876, https:/| doi.org/10.1039/C4TA03445G.

[36] A. Ghobadi, H.I. Yavuz, T.G. Ulusoy, K.C. Icli, M. Ozenbas, A.K. Okyay, Enhanced performance of nanowire-based all- $\mathrm{TiO}_{2}$ solar cells using subnanometer-thick atomic layer deposited $\mathrm{ZnO}$ embedded layer, Electrochim. Acta 157 (2015) 23-30, https://doi.org/10.1016/j.electacta.2015.01.079.

[37] A. Ghobadi, T.G. Ulusoy, R. Garifullin, M.O. Guler, A.K. Okyay, A heterojunction design of single layer hole tunneling $\mathrm{ZnO}$ passivation wrapping around $\mathrm{TiO}_{2}$ nanowires for superior photocatalytic performance, Sci. Rep. 6 (2016) 30587 . https://doi.org/10.1038/srep30587.

[38] S. Song, S. Yao, J. Cao, L. Di, G. Wu, N. Guan, et al., Heterostructured Ni/NiO composite as a robust catalyst for the hydrogenation of levulinic acid to $\gamma$ valerolactone, Appl. Catal. B Environ. 217 (2017) 115-124, https://doi.org/ 10.1016/j.apcatb.2017.05.073. 